\title{
SIMULAÇÃO DA EVOLUÇÃO DO REBANHO CONSIDERANDO POTENCIAL DE CRESCIMENTO E HABILIDADE MATERNA COMO CRITÉRIOS DE SELEÇÃO EM BOVINOS DE CORTE
}

\author{
Herd evolution simulation considering growth potential and maternal ability as \\ selection criteria in beef cattle
}

\author{
PAULA, E.J.H. ${ }^{1}$; MAGNABOSCO, C.U. ${ }^{2}$; VIU, M.A.O. ${ }^{3}$; LOPES, D.T. ${ }^{3}$; BARIONI, L.G. ${ }^{2}$; \\ SAUERESSIG, M.G. ${ }^{2}$; MARTHA JUNIOR, G.B. ${ }^{2}$; SAINZ, R.D. ${ }^{4}$
}

1 Zootecnista, professor do departamento de Zootecnia da Universidade do Estado do Mato Grosso

2 Embrapa Cerrados

3 Universidade Federal de Goiás

${ }^{4}$ University of California

Endereço para correspondência: Edson Júnior Heitor de Paula: edsonjr@unemat.br

\section{RESUMO}

O objetivo deste trabalho foi verificar, por meio de simulação, o resultado de vinte anos de seleção para crescimento e habilidade materna na produtividade de um rebanho Nelore puro de origem (PO), marca BRGN (Nelore BRGN), criado no bioma Cerrado. O modelo de simulação utilizado foi o DECl (Decision Evaluator for the Industry Cattle), ao qual foram informados os dados de forma a refletir, o mais fielmente possível, o sistema de produção do rebanho Nelore da Embrapa Cerrados. O modelo de simulação DECI foi eficaz em predizer a resposta à seleção genética para habilidade materna que obteve como resposta direta o aumento de 5,5\% na produção de leite, proporcionando maior ganho de peso pré-desmama (9,3\%) e aumento no peso do bezerro a desmama (10\%). No entanto, foram verificadas maiores médias para peso à maturidade $(465 \mathrm{~kg}$ ), peso da vaca ao parto $(476 \mathrm{~kg}$ ), e peso da vaca na desmama (520 kg), indicando maiores custos de manutenção do rebanho devido ao aumento no tamanho corporal e nas exigências de mantença desses animais. A maior produção de leite das mães acarretou diminuição na condição corporal ao parto $(9,3 \%)$ e à desmama $(3,9 \%)$. Sob as condições estudadas, a adoção das técnicas de manejo resultantes da simulação poderá aumentar as taxas produtivas do rebanho Nelore da Embrapa Cerrados.

Palavras-chave: cerrado; Nelore; predição; produção animal

\section{ABSTRACT}

The aim of this study was to verify, by simulation, the result of twenty years of selection for maternal ability and growth in productivity in a selection Nellore herd raised in the savannah biome. Data were reported to the DECl (Decision Evaluator for the Industry Cattle) simulation model reflecting the real situation of registered purebred Nellore herd of the Embrapa Cerrados (Nellore BRGN). The simulation model DECI was effective to predict the response to genetic selection for high growth rate and maternal ability, signaling direct improvement in the response of $5.5 \%$ in milk yield causing an increased pre-weaning weight gain (9.3\%), and the weaning weight of calf (10\%). However, were found increased, the average maturity weight (465 kg), the weight of the cow in the moment of the partum $(476 \mathrm{~kg})$, and the weaning weight of the cow $(520 \mathrm{~kg})$. These results indicate higher costs for herd maintenance due to the increase in body size and together, the requirements for maintenance of these animals. The increased milk yield of mothers caused a decrease in body condition of delivery (9.3\%) and weaning (3.9\%). Under the simulated conditions, the adoption of the management techniques resulted from the simulation may increase the productive rates of the Nellore Embrapa Cerrados herd.

Key words: animal production; Nellore; predict; savanna 


\section{INTRODUÇÃO}

A intensificação do uso da terra tem aumentado a pressão da exploração dos recursos naturais renováveis e causado degradação ambiental em grandes áreas. Cerca de $80 \%$ das pastagens cultivadas no Brasil Central, responsáveis por mais de $55 \%$ da produção de carne nacional estão com algum grau de degradação (Peron e Evangelista, 2004). Por algum tempo a diminuição da produção nessas áreas degradadas era compensada com a abertura de novas áreas, por exemplo, as fronteiras agrícolas do Mato Grosso e Pará. Essa abertura cessou diante da imposição de nova legislação ambiental que forçou os produtores a buscarem opções com o objetivo de aumentar a produtividade no sistema de produção, sendo uma dessas, o melhoramento genético do rebanho.

De acordo com McManus et al. (2002), o processo de seleção deve objetivar a obtenção do genótipo bovino adequado ao sistema de produção de ciclo curto, sem aumentar as exigências nutricionais, alterando as formas das curvas de crescimento corporal e de desenvolvimento/maturação sexual, mantendo ou reduzindo o tamanho adulto, a necessidade de mantença e a idade de terminação ou acabamento de carcaças. $O$ problema da seleção em bovinos é o longo intervalo de geração e, por isso, tomadas de decisões para as características econômicas a serem selecionadas precisam ser bastante discutidas e pautadas no tempo (Meirelles, 2005).

Dessa forma, a simulação computacional ou modelagem matemática é uma ferramenta de baixo custo e eficiente na análise do impacto das mudanças nas diferentes estratégias de manejo utilizadas (Tess e Kostald, 2000).

Na literatura brasileira existem poucos trabalhos que usaram modelos de simulação em sistemas de produção de gado de corte na região dos Cerrados
(Magnabosco et al., 2006). Entretanto, em países de clima temperado, os modelos de simulação têm sido utilizados com sucesso para auxílio à pesquisa e na tomada de decisões em fazendas (Tess e Kolstad, 2000; Williams et al., 2006).

O objetivo deste trabalho foi verificar o resultado de vinte anos de seleção para crescimento e habilidade materna em um rebanho de bovinos Nelore puro de origem (PO) criado no bioma Cerrado, usando-se um modelo de simulação.

\section{MATERIAL E MÉTODOS}

O estudo foi conduzido com dados provenientes da fazenda experimental da Embrapa Cerrados - Centro de Pesquisa Agropecuária dos Cerrados (CPAC), que está localizada no km 18 da BR 020, no município de Planaltina-DF, com altitude média de $1100 \mathrm{~m}$, latitude sul de $15^{\circ} 45^{\prime} \mathrm{e}$ longitude oeste de $47^{\circ} 25^{\prime}$ na qual são destinados 380 hectares de Cerrado para pastagens cultivadas. A temperatura média anual é de $20,5^{\circ} \mathrm{C}$ e o índice pluviométrico de $1300 \mathrm{~mm}$.

O modelo de simulação utilizado foi o DECI (Decision Evaluator for the Industry Cattle), desenvolvido por pesquisadores do USDA - Meat Animal Research Center (MARC), Clay Center, Nebraska-USA (Williams e Jenkins, 2000).

Foram realizadas simulações com espaço temporal de vinte anos, sendo que os primeiros cinco anos foram descartados para evitar a interferência dos valores iniciais sobre os resultados.

Nesta simulação utilizou-se a média dos dados reais de produção das safras de 1999 a 2006. O rebanho informado ao DECl era constituído de 229 fêmeas em reprodução, com estação de nascimento entre o início de julho e final de novembro de cada ano e bezerros desmamados com idade variando de 7 a 10 meses. Todas as crias foram pesadas ao nascer e a cada 90 
dias até completarem 24 meses de idade. A relação touro/vaca utilizada foi de 1/30 e o tempo de permanência dos touros no rebanho era de um ano. Todas as fêmeas em reprodução foram pesadas e passaram por diagnóstico de gestação na época da desmama, por meio do exame ginecológico. As novilhas foram colocadas em estação reprodutiva com, pelo menos, 24 meses de idade. As vacas que permaneceram vazias ao final da estação de monta (EM) foram descartadas, e as novilhas mantidas, sendo estas expostas à reprodução na EM do verão subsequente. A duração da EM foi de 90 dias para as vacas (de 01/11 a 31/01) e 120 dias para as novilhas (01/10 a 31/01). A cada ano foram retidas 50 bezerras à desmama para reposição.

O rebanho Nelore, puro de origem (PO), marca BRGN da Embrapa Cerrados é participante do Programa de Melhoramento Genético da Raça Nelore PMGRN, tendo como objetivo principal selecionar animais geneticamente superiores para crescimento e habilidade materna, considerando o bioma Cerrado. Foram utilizados apenas touros Nelore PO que apresentaram alto potencial de crescimento e habilidade maternal quando comparados às médias nacionais disponibilizadas pelo PMGRN.

Os animais eram mantidos em pastagens cultivadas de braquiária (Brachiaria decumbens e B. brizantha cv. Xaraés), andropógon (Andropogon gayanus) e consorciadas de $B$. decumbens com estilosantes (Stylosanthes guyanenses cv. Mineirão). As informações referentes à oferta e qualidade de forragem foram baseadas em análises bromatológicas realizadas em amostras coletadas nas áreas de pastagem da Embrapa Cerrados. As categorias animais e período de pastejo das forrageiras são apresentados na Tabela 1.

Os pastos quando não utilizados pelo rebanho Nelore PO eram disponibilizados para outras categorias animais presentes na fazenda, e em determinados períodos eram vedados para servirem como reserva de forragem para o período seco do ano.

$\mathrm{Na}$ Tabela 2 são apresentadas informações de proteína bruta (PB), nutrientes digestíveis totais (NDT) e disponibilidade potencial das forrageiras utilizadas durante 0 ano para a alimentação do rebanho. O programa de suplementação constituiu-se de suplemento protéico durante a seca (meses de junho a outubro) para todos os animais. Durante as águas (novembro a maio), os animais recebiam apenas sal mineralizado. O controle de consumo da mistura mineral foi mensal, obtido pela diferença de pesagem entre fornecido e sobras. A suplementação energética para bezerros foi feita pelo sistema creepfeeding. Na Tabela 3 estão sumarizadas as informações em relação ao período de consumo, quantidade, valor nutricional do suplemento e categoria animal suplemen-

Tabela 1 - Período de utilização das forrageiras disponíveis na Embrapa Cerrados de acordo com a categoria animal

\begin{tabular}{|c|c|c|c|c|c|c|c|c|}
\hline \multirow{4}{*}{$\begin{array}{l}\text { Categoria } \\
\text { Animal }\end{array}$} & \multicolumn{8}{|c|}{ Forrageiras } \\
\hline & \multicolumn{2}{|c|}{$\begin{array}{l}\text { Andropogon } \\
\text { gayanus }\end{array}$} & \multicolumn{2}{|c|}{$\begin{array}{l}\text { Brachiaria } \\
\text { decumbens }\end{array}$} & \multicolumn{2}{|c|}{$\begin{array}{c}\text { B. brizantha cv. } \\
\text { Xaraés }\end{array}$} & \multicolumn{2}{|c|}{$\begin{array}{c}\text { B. decumbens }+S \text {. } \\
\text { guyanenses cv. Mineirão }\end{array}$} \\
\hline & \multicolumn{8}{|c|}{ Época de pastejo } \\
\hline & Início & Fim & Início & Fim & Início & Fim & Início & Fim \\
\hline Vacas & $1 /$ nov & 31/jan & 1/jun & 31/out & $1 /$ fev & $31 /$ mai & - & - \\
\hline Bezerros & $1 /$ nov & 31/jan & - & - & $1 /$ fev & 31/mai & 1/abril & 31/out \\
\hline Novilhas & $1 /$ nov & 31/jan & - & - & $1 /$ fev & $1 /$ jun & 2/jun & 31/out \\
\hline Touros & $1 /$ nov & 31/jan & $1 / \mathrm{mai}$ & $31 /$ out & $1 / \mathrm{fev}$ & $30 / a b r$ & - & - \\
\hline
\end{tabular}


Tabela 2 - Proteína bruta (PB), Nutrientes Digestíveis Totais (NDT) e disponibilidade potencial (kg MS/cab/dia) das forrageiras disponíveis para o rebanho Nelore da Embrapa Cerrados

\begin{tabular}{|c|c|c|c|c|c|c|c|c|c|c|c|c|c|}
\hline \multirow{2}{*}{ Forrageira } & \multirow{2}{*}{ Itens } & \multicolumn{12}{|c|}{ Meses } \\
\hline & & Jan & Fev & Mar & Abr & Mai & Jun & Jul & Ago & Set & Out & Nov & Dez \\
\hline \multirow[t]{3}{*}{$\begin{array}{l}\text { Andropogon } \\
\text { gayanus }\end{array}$} & $\begin{array}{l}\text { Proteína Bruta } \\
\text { (\% da MS) }\end{array}$ & 9,7 & 11,0 & 10,5 & 9,0 & 8,0 & 6,0 & 5,6 & 4,2 & 4,6 & 4,8 & 6,0 & 8,2 \\
\hline & NDT, ( $\%$ da MS) & 59,0 & 60,2 & 59,0 & 55,0 & 53,0 & 50,0 & 48,1 & 45,1 & 45,0 & 48,1 & 52,0 & 56,0 \\
\hline & Disponibilidade & 22,5 & 23,2 & 22,2 & 21,1 & 20,0 & 19,3 & 18,9 & 17,2 & 17,0 & 17,3 & 18,0 & 20,6 \\
\hline \multirow[t]{3}{*}{$\begin{array}{l}\text { Brachiaria } \\
\text { decumbens }\end{array}$} & $\begin{array}{l}\text { Proteína Bruta } \\
\text { (\% da MS) }\end{array}$ & 11,9 & 7,7 & 7,5 & 8,7 & 7,0 & 5,1 & 6,5 & 7,4 & 8,4 & 9,6 & 9,0 & 10,2 \\
\hline & NDT, (\% da MS) & 59,1 & 56,6 & 55,0 & 54,0 & 49,3 & 47,1 & 50,5 & 52,8 & 47,8 & 56,6 & 63,6 & 61,4 \\
\hline & Disponibilidade & 22,7 & 22,2 & 21,1 & 20,0 & 19,3 & 18,6 & 17,9 & 17,4 & 17,0 & 18,0 & 18,8 & 23,2 \\
\hline \multirow[t]{3}{*}{$\begin{array}{l}\text { B. brizantha } \\
\text { Cv. Xaraés }\end{array}$} & $\begin{array}{l}\text { Proteína Bruta } \\
\text { (\% da MS) }\end{array}$ & 13,5 & 11,3 & 10,1 & 9,6 & 8,3 & 8,9 & 6,3 & 7,1 & 9,7 & 11,2 & 13,0 & 13,4 \\
\hline & NDT, (\% da MS) & 61,2 & 58,2 & 56,7 & 55,5 & 54,0 & 53,5 & 49,4 & 51,2 & 54,3 & 56,1 & 58,5 & 59,3 \\
\hline & Disponibilidade & 23,2 & 22,9 & 22,5 & 21,8 & 20,0 & 19,3 & 17,8 & 17,2 & 17,5 & 17,5 & 18,0 & 20,0 \\
\hline \multirow{2}{*}{$\begin{array}{l}\text { B. decumbens } \\
+ \text { +S.guyanensis } \\
\text { Cv. Mineirão }\end{array}$} & $\begin{array}{l}\text { Proteína Bruta } \\
\text { (\% da MS) }\end{array}$ & 12,3 & 9,8 & 9,3 & 9,0 & 7,8 & 6,1 & 7,4 & 8,2 & 8,9 & 10,4 & 11,0 & 11,8 \\
\hline & $\begin{array}{l}\text { NDT, (\% da MS) } \\
\text { Disnonibilidade }\end{array}$ & $\begin{array}{l}59,6 \\
525\end{array}$ & $\begin{array}{l}57,9 \\
203\end{array}$ & 56,9 & 55,3 & 51,0 & 48,6 & 52,0 & 54,1 & 49,3 & 57,1 & 64,3 & 62,4 \\
\hline
\end{tabular}

Tabela 3 - Valor nutricional, consumo e período de utilização do suplemento protéico por categoria animal durante a seca

\begin{tabular}{lccccc}
\hline \multirow{2}{*}{ Lotes de manejo } & \multicolumn{2}{c}{$\begin{array}{c}\text { Consumo em } \\
\text { quilogramas }(\mathrm{kg})\end{array}$} & \multicolumn{2}{c}{ Valor Nutricional } & \multicolumn{2}{c}{ Período de utilização } \\
\cline { 3 - 6 } & & PB (\%) & NDT (\%) & Início & Fim \\
\hline Vacas multíparas & 0,250 & 46 & 34,1 & $01 / \mathrm{jul}$ & $01 /$ out \\
Vacas primíparas & 0,250 & 46 & 34,1 & $01 / \mathrm{jul}$ & $01 /$ out \\
Bezerros & 0,080 & 16 & 70,0 & $11 / \mathrm{set}$ & $15 / \mathrm{mai}$ \\
Novilhas & 0,150 & 46 & 34,1 & $01 / \mathrm{jul}$ & $01 /$ out \\
Touros & 0,300 & 46 & 34,1 & $01 / \mathrm{jul}$ & $01 /$ out \\
\hline
\end{tabular}

tada.

Buscou-se, por meio de simulação, predizer o comportamento e a associação biológica de algumas características produtivas tais como: peso ao nascimento $(\mathrm{PN})$, peso do bezerro à desmama (PDB), ganho médio diário pré-desmame (GMD), peso à maturidade $(\mathrm{PM})$, peso da vaca ao parto (PVP), condição corporal da vaca ao parto (CCP), peso da vaca à desmama (PVD), condição corporal da vaca à desmama (CCD) e produção de leite (PL). Os resultados obtidos na simulação foram submetidos à análise de variância e posterior análise de regressão, utilizandose os procedimentos GLM e REG do programa SAS (SAS, 1997).

\section{RESULTADOS E DISCUSSÃO}

De acordo com Martins et al. (2000), nos bovinos, de maneira geral, os machos são mais pesados não só ao nascer mas em todas as idades, e essa diferença pode ser atribuída à capacidade genética dos machos apresentarem maiores índices de crescimento pré e pós-natal, devido a fatores hormonais. McManus et al. (2002) relataram que 0 peso ao nascimento superior dos machos é justificado pela ação precoce da testosterona, que determina taxa metabólica mais acentuada do feto durante o período de gestação.

Entretanto, verificou-se que o peso ao nascimento (PN) não apresentou variações 
Tabela 4 - Simulação do peso ao nascimento (PN) dos bezerros de um rebanho Nelore criado extensivamente no Cerrado

\begin{tabular}{lcccccccc}
\hline \multirow{2}{*}{ Peso ao nascimento $(\mathrm{kg})$} & \multicolumn{7}{c}{ Ano da simulação } \\
\cline { 2 - 9 } & 6 & 7 & 8 & 9 & 10 & 11 & 12 & 13 \\
\hline Machos & 28,1 & 28,6 & 28,1 & 28,6 & 29,0 & 28,6 & 29,0 & 28,6 \\
Fêmeas & 26,8 & 26,8 & 27,2 & 26,8 & 26,8 & 26,8 & 26,3 & 26,8 \\
\hline \multirow{2}{*}{ Peso ao nascimento $(\mathrm{kg})$} & \multicolumn{7}{c}{ Ano da simulação } \\
\cline { 2 - 9 } & 14 & 15 & 16 & 17 & 18 & 19 & 20 & Média \\
\hline Machos & 28,6 & 28,6 & 28,6 & 28,6 & 28,6 & 28,6 & 28,6 & 28,6 \\
Fêmeas & 27,2 & 26,8 & 26,8 & 26,8 & 26,8 & 26,8 & 26,8 & 26,8 \\
\hline
\end{tabular}

significativas para machos e fêmeas, durante os vinte anos de estudo de simulação (Tabela 4). Os resultados obtidos são coerentes, uma vez que os touros utilizados na simulação de acasalamentos com as vacas multíparas e novilhas apresentavam, respectivamente, médio e baixo potenciais para PN.

Tabela 5 - Médias de peso ao nascer (PN) do rebanho Nelore marca BRGN da Embrapa Cerrados, de 2001 a 2005

\begin{tabular}{ccccc}
\hline \multirow{2}{*}{ Ano } & \multicolumn{2}{c}{ Machos } & \multicolumn{2}{c}{ Fêmeas } \\
\cline { 2 - 5 } & $\begin{array}{c}\text { Média } \\
\text { em kg }\end{array}$ & $\begin{array}{c}\mathrm{N}^{0} . \text { de } \\
\text { animais }\end{array}$ & $\begin{array}{c}\text { Média em } \\
\mathrm{kg}\end{array}$ & $\begin{array}{c}\mathrm{N}^{0} . \text { de } \\
\text { animais }\end{array}$ \\
\hline 2001 & 34 & 20 & 32 & 28 \\
2002 & 33 & 18 & 31 & 30 \\
2003 & 32 & 53 & 31 & 38 \\
2004 & 34 & 18 & 34 & 39 \\
2005 & 34 & 33 & 33 & 28 \\
\hline
\end{tabular}

Magnabosco et al. (1994), após revisão de literatura, concluíram que o pai do bezerro influencia diretamente o PN e outras características, como duração da gestação e produção de leite da mãe. Segundo Martins et al. (2000), a seleção de reprodutores deve merecer atenção quando se estabelece um programa de melhoramento genético, pois touros de grande porte produzem bezerros mais pesados ao nascer e promovem incremento no tamanho adulto, o que é indesejável (Alencar, 2002). Por essa razão, a DEP para $P N$ é utilizada para monitorar e não para selecionar os animais, de modo a evitar aumento significativo desta característica.
Os resultados obtidos foram inferiores aos encontrados por Scarpati e Lôbo (1999) que, ao analisarem 6.511 nascimentos de animais da raça Nelore, de ambos os sexos, obtiveram média de 31,0 $\pm 4,1 \mathrm{~kg}$. Resultados mais próximos foram encontrados por Martins et al. (2000), 29,5 e 28,0 kg para PN de machos e fêmeas da raça Nelore, respectivamente.

$\mathrm{Na}$ Tabela 5 estão apresentadas as médias de PN reais de 2001 a 2005 dos bezerros do rebanho Nelore marca BRGN.

$O$ peso à desmama (PBD) de machos e fêmeas apresentou variação significativa $(P<0,01)$ ao final dos 20 anos de simulação, sendo respectivamente, $250 \mathrm{e}$ $227 \mathrm{~kg}$, conforme demonstra a Figura 1. A média de idade à desmama foi de $235 \mathrm{e}$ 237 dias para os machos e fêmeas, respectivamente. $O$ PBD de machos aumentou de 225 para $250 \mathrm{~kg}$ nos 15 últimos anos de simulação e as fêmeas passaram de $208 \mathrm{~kg}$ de PBD para, $227 \mathrm{~kg}$ no final do período simulado, o que representa aumento de $11,1 \%$ e $9,1 \%$, respectivamente.

A habilidade materna da vaca, o genótipo do bezerro e o meio ambiente são fatores determinantes no desempenho do bezerro do nascimento à desmama (Viu et al. 2006). Os pesos à desmama obtidos neste estudo foram superiores aos relatados por Viu et al. (2006) e Jorge Júnior et al. (2006), (189,0 $\pm 21,8,178,3 \pm$ 20,0; 180 e $160 \mathrm{~kg}$ de PBD para machos e fêmeas, respectivamente). Isto evidencia a resposta à seleção para habilidade mater- 


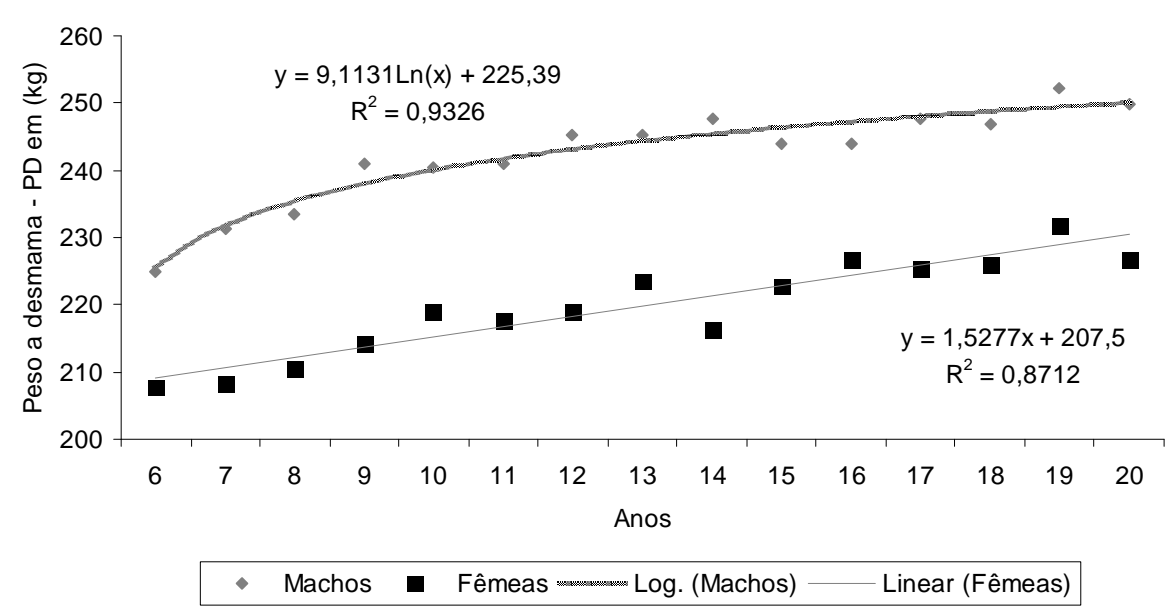

Figura 1 - Pesos simulados de machos e fêmeas à desmama (235 dias), em um rebanho seleção de Nelore no Cerrado.

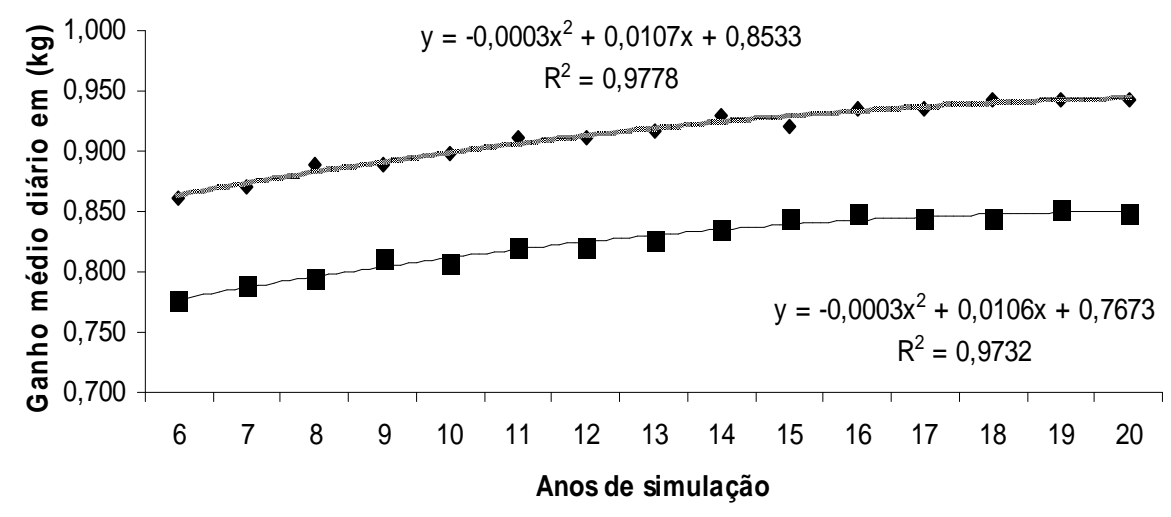

- Machos 【 Fêmeas —_Polinômio (Fêmeas) …....Polinômio (Machos)

Figura 2 - Ganhos médios diários pré-desmame simulados para machos e fêmeas, do sexto ao vigésimo ano em um rebanho seleção de Nelore no Cerrado.

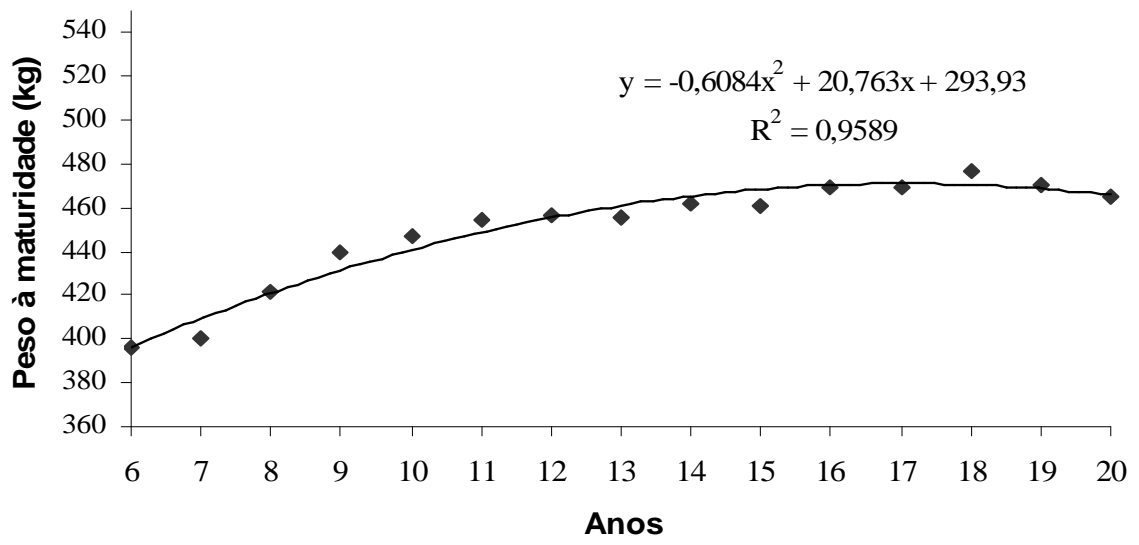

Figura 3 - Evolução da média do peso à maturidade do sexto ao vigésimo ano de simulação no rebanho BRGN. 
na (produção de leite das matrizes) e para crescimento.

Segundo Lobato et al. (1998), bons pesos à desmama, independente do sexo, e bons ganhos de peso pós-desmama são fundamentais para atingir o peso de abate ideal o mais rapidamente possível e a puberdade precoce em novilhas. De acordo com Silveira et al. (2004), o PBD é pouco influenciado pela ação gênica aditiva (seleção) e muito pelo manejo nutricional e sanitário adotado na propriedade. Porém, nesta simulação, o manejo nutricional e sanitário do rebanho não foi modificado com o passar dos anos simulados, logo as respostas em aumento do PBD se deram pela ação genética aditiva promovida pelo melhoramento genético atingido no potencial de crescimento e em produção de leite das matrizes.

Os PBD's obtidos pela simulação ao final de 20 anos de seleção para crescimento e habilidade materna $(250 \mathrm{e}$ $227 \mathrm{~kg}$ para machos e fêmeas respectivamente) foram superiores aos mensurados nos anos de 1999 a 2006 que apresentaram média de 190 e $182 \mathrm{~kg}$ para machos e fêmeas. Este comportamento já era esperado devido a seleção para habilidade materna o que promove um aumento na produção de leite das mães, e resposta no mesmo sentido em PBD.

Os GMD's obtidos por simulação foram de 0,943 e $0,848 \mathrm{~kg}$ para machos e fêmeas, respectivamente (Figuras 2).

Esses resultados quando submetidos à análise de regressão apresentaram variação significativa $(P<0,01)$ e são considerados altos quando comparados com os publicados na literatura para a raça Nelore. Viu et al. (2006), estudando 2.973 bezerros Nelore PO nascidos entre 1992 e 2003, criados em pastagem na região do Cerrado brasileiro, sem suplementação por creep-feeding, relataram GMD prédesmame de $0,590 \pm 0,09 \mathrm{~kg}$ para machos e $0,547 \pm 0,08 \mathrm{~kg}$ para fêmeas. Neste estudo, os animais foram produto de gerações consecutivas de seleção para crescimento, e suas mães também foram selecionadas para habilidade maternal, 0 que influenciou diretamente o GMD dos bezerros, principalmente nos 120 dias iniciais. Além do criterioso diferencial de seleção, houve também o melhoramento ambiental, pois os bezerros tiveram acesso ao creep-feeding durante todo o período de aleitamento, o que ajuda a explicar os altos desempenhos.

Segundo Muniz et al. (2005), o desempenho do bezerro até a desmama é consequência de seu potencial para crescimento e da habilidade materna de sua mãe. A produção de leite é o principal fator no desenvolvimento do bezerro, tendo coeficiente de correlação de 0,6 , em média, entre produção de leite da vaca e peso do bezerro à desmama.

Com relação ao peso maduro (PM), nesta simulação, o mesmo passou de 396 $\mathrm{kg}$ no sexto ano para $465 \mathrm{~kg}$ no último (Figura 3$)$, variação significativa $(P<0,01)$ para as médias de PM foram obtidas. Esses resultados concordam com dados da literatura que demonstram alta correlação entre seleção para alto potencial de crescimento e aumento no PM (McManus et al. 2002).

De acordo com Talhari et al. (2003), vários trabalhos têm mostrado que em sistemas de criação extensiva, o maior peso à maturidade está associado com maior incidência de distocia, períodos de gestação mais longos, menores taxas de parição, custos mais altos para manutenção dos rebanhos de vacas, redução da eficiência reprodutiva, intervalos de partos mais longos, maior idade ao primeiro parto e menor taxa de concepção durante a vida útil da vaca. Porém, Mercadante et al. (2002) trabalharam com o rebanho seleção Nelore do Instituto de Zootecnia (IZ) e chegaram à conclusão que a seleção para crescimento não influenciou no desempenho reprodutivo das fêmeas apesar de ter aumentado o PM. 
Marshall et al. (1983) e Marshall et al. (1987) verificaram que a relação entre o número de bezerros desmamados e 0 peso das vacas não era linear, diminuindo a partir de um determinado peso das vacas. Por outro lado, a quantidade de energia metabolizável consumida pelas vacas durante a vida útil, apresentou relação linear com o peso à maturidade das mesmas. Estes resultados indicam que existe um peso ótimo das vacas quanto à eficiência da produção com base no peso à desmama dos bezerros. Assim, a decisão sobre qual deve ser a variação aceitável para o tamanho das vacas pode variar de acordo com os recursos genéticos e ambientais disponíveis, bem como com os custos de manutenção dos diferentes sistemas de produção de bovinos de corte.

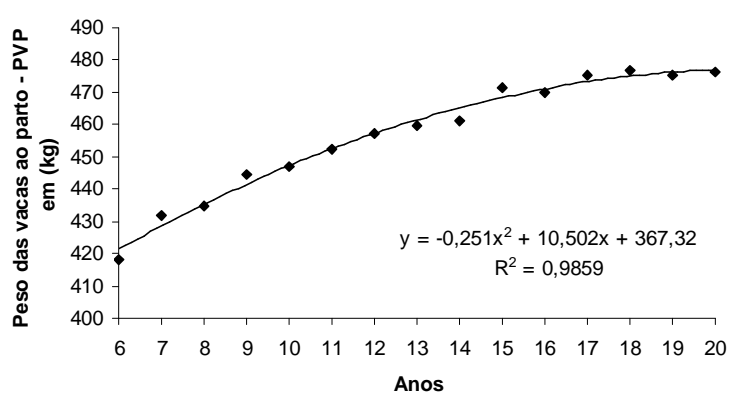

Figura 4 - Pesos médios das vacas na ocorrência do parto simulados do sexto ao vigésimo ano em um rebanho seleção de Nelore PO no Cerrado.

O peso médio da vaca ao parto (PVP) das vacas Nelore do rebanho seleção da Embrapa Cerrados, quando simulados por 20 anos, aumentou em 13,8\% e a diferença média verificada foi significativa $(P<0,01)$. Ao longo dos 15 últimos anos da simulação (Figura 4), o peso aumentou de $418 \mathrm{~kg}$ para $476 \mathrm{~kg}$, resultado que pode ser explicado pelo uso de touros com maiores DEPs para crescimento. Em geral, as vacas maiores produzem mais leite e desmamam bezerros mais pesados, o que é desejável em sistemas de produção intensivos, em que o manejo nutricional é adequado (Alencar et al. 1997). Os mesmos autores ao trabalharem com vacas da raça Nelore criadas na região Oeste de São Paulo relataram PVP de 409 $\pm 1 \mathrm{~kg}$, inferior, portanto ao verificado nesta simulação.

Em outro estudo, Alencar et al. (1999), utilizando dados de animais Nelore pertencentes ao rebanho de bovinos de corte da Embrapa Pecuária do Sudeste (CPPSE), situado no município de São Carlos - SP, encontraram média de PVP de $450 \mathrm{~kg}$ e variação de PVP de acordo com o mês do parto; obtiveram média de $426 \pm 5 \mathrm{~kg}$ para os partos ocorridos em outubro e $487 \pm 7$ para partos em maio.

$\mathrm{Na}$ Figura 5 pode-se observar que a condição corporal das vacas ao parto (CVP) diminuiu ao longo dos vinte anos de simulação, passando de 4,7 para 4,4, com perda de 9,3 pontos percentuais $(P<0,01)$, lembrando que o modelo $\mathrm{DECl}$ utiliza a escala de um a nove pontos, descrita por Herd e Sprot (1996). Ainda de acordo com esses autores, neste método de avaliação, os escores entre quatro e oito pontos seriam desejáveis por não afetarem negativamente a reprodução do rebanho.

Segundo Silva et al. (2005), a condição corporal da fêmea logo após o parto influencia o período da involução uterina, que determina o retorno da atividade ovariana. Os autores ressaltaram que nesta fase a fêmea está em balanço energético negativo, e a boa condição corporal é condição essencial para aumentar a eficiência reprodutiva do rebanho.

O peso da vaca à desmama (PVD) é um dado zootécnico valioso, pois ao compará-lo com o PBD pode-se avaliar a habilidade da vaca como progenitora, considerando-se como boa mãe, aquela que desmama bezerro com, aproximadamente, $50 \%$ do seu peso.

Nesta simulação, o PVD apresentou diferença significativa $(P<0,01)$ e atingiu $520 \mathrm{~kg}$ ao final de 20 anos, com aumento linear até o décimo oitavo ano e nos últimos 2 anos uma estabilização, como pode ser visto na Figura 6. 


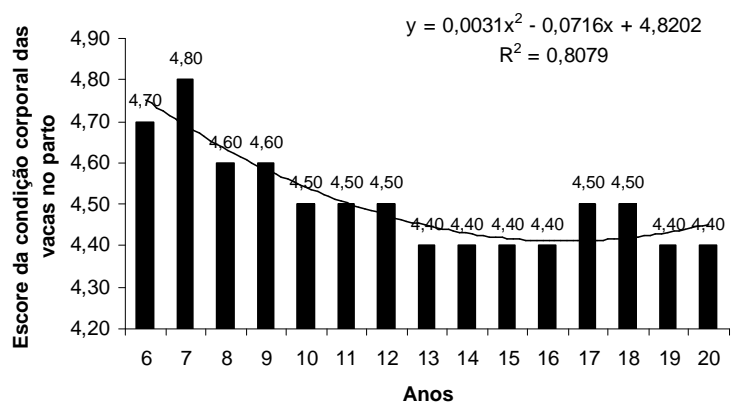

Figura 5 - Escores da condição corporal das vacas na ocorrência do parto, simulados por 20 anos em um rebanho seleção de Nelore no Cerrado.

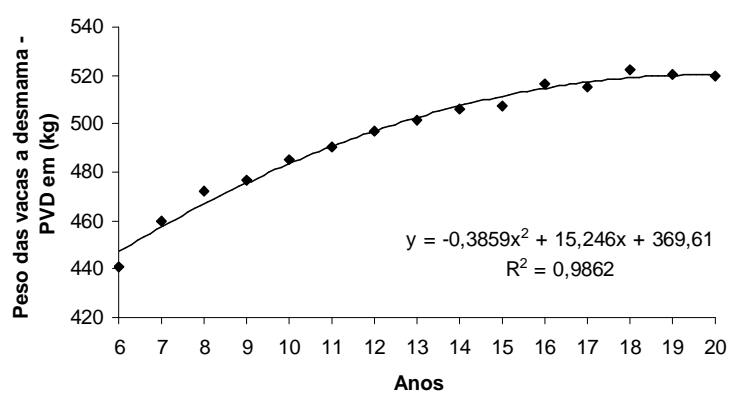

Figura 6 - Evolução dos pesos das vacas à desmama, simulados por 20 anos em um rebanho seleção de Nelore criado extensivamente no Cerrado.

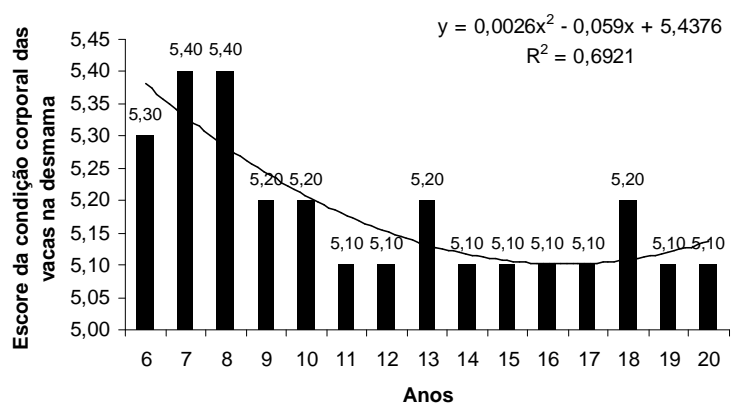

Figura 7 - Evolução dos escores da condição corporal das vacas à desmama, simulados do sexto ao vigésimo ano de seleção.

De acordo com Talhari et al. (2003), a correlação genética positiva entre peso em idades jovens e peso adulto ou à maturidade em fêmeas bovinas de corte indica que a seleção para peso deve aumentar o peso adulto das vacas do rebanho. Este é um ponto relevante, principalmente no Brasil, onde a maioria dos sistemas de criação é extensivo, havendo grande flutuação sazonal na produção de forragens, fazendo com que o tamanho da vaca seja fator determinante da eficiência biológica e econômica dos sistemas de produção de bovinos de corte.

$A$ condição corporal das vacas à desmama (CVD) diminuiu de 5,30 para 5,10 durante os 20 anos de simulação, demonstrando variação significativa $(P<0,01)$, conforme Figura 7 .

Apesar da diminuição da condição corporal dos animais à desmama (Figura 7), a queda não ultrapassou o limite de 5 , apontado por Valle et al. (2000) como limite inferior para que não ocorra queda na eficiência reprodutiva do sistema de produção. A queda da CVD pode ter ocorrido em função da seleção para habilidade materna, o que aumentou a exigência de energia e outros nutrientes para a maior produção de leite.

A avaliação da condição corporal das fêmeas é uma ferramenta útil no manejo reprodutivo, pois, apesar de subjetiva, reflete o estado nutricional do rebanho em determinado momento. $O$ emprego desta prática, em condições estratégicas, permite que correções no manejo nutricional possam ser realizadas, de modo que os animais apresentem condições mínimas no momento desejado (Valle et al. 2000).

Segundo Frizzo et al. (2003), a importância da condição corporal para sistemas de produção pode ser observada pelos valores dos coeficientes de correlação desta variável com a porcentagem de estro $(0,98 ; P<0,01)$, o peso à puberdade $(0,96 ; P<0,01)$ e idade à puberdade $(0,96 ; \mathrm{P}<0,01)$.

A produção de leite das vacas Nelore $\mathrm{PO}$, do sexto ao vigésimo ano de simulação está apresentada na Figura 8.

Houve, com o passar dos anos, acréscimo de $5,5 \%$ na produção de leite $(\mathrm{P}<0,01)$, chegando à média de 6,17 $\mathrm{kg} / \mathrm{vaca} / \mathrm{dia}$, quantidade suficiente para garantir os altos desempenhos dos bezerros tanto em GMD quanto em PBD.

Segundo McManus et al. (2002), a habilidade materna é um conjunto de atri- 


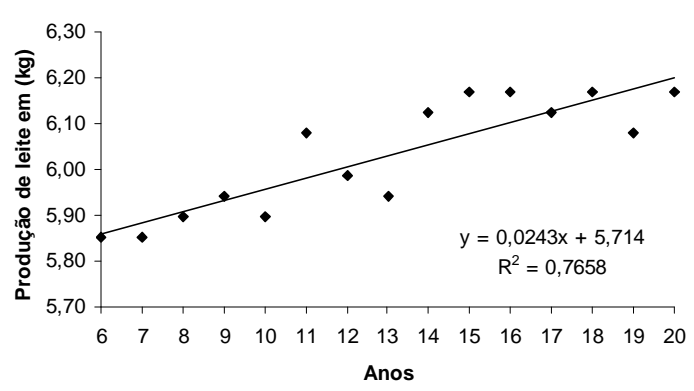

Figura 8 - Produções de leite das vacas do sexto ao vigésimo ano de simulação, do rebanho seleção de Nelore da Embrapa Cerrados.

butos que a vaca deve possuir para fornecer o melhor desenvolvimento possível à sua cria, incluindo imunidade passiva, atenção, proteção e capacidade genética de adaptação, mas, principalmente, produção de leite. No estudo de Ribeiro e Restle (1991) a produção de leite foi responsável por $56 \%$ da variação do peso do bezerro à desmama.

Portanto, a seleção para baixos e moderados PN, alto potencial de crescimento e habilidade materna, pela utilização de touros com DEPs apropriadas, proporcionou, durante os 20 anos de simulação, melhorias no rebanho seleção Nelore da Embrapa Cerrados, principalmente nos 17 primeiros anos, pois pode-se observar que nos últimos três anos algumas características (GMD, PBD, PVD, PVP, PM) praticamente se estabilizaram, o que sugere a necessidade de melhorias no manejo nutricional. A seleção para habilidade materna teve como resposta direta o aumento de 5,5\% na produção de leite, proporcionando maior ganho de peso pré-desmama $(9,3 \%)$ e aumento do PBD (10\%). Porém, foram verificadas maiores médias para PM (465 kg), PVP (476 kg), e PVD (520 kg), indicando maiores custos de manutenção do rebanho devido ao aumento no tamanho corporal e, concomitantemente, nas exigências de mantença desses animais.
A maior produção de leite das mães causou a diminuição na condição corporal do parto $(9,3 \%)$ e à desmama $(3,9 \%)$. Durante a simulação não foram realizadas mudanças no sistema nutricional fornecido aos animais e este se mostrou capaz de atender os requerimentos dos animais selecionados, teoricamente, mais exigentes nutricionalmente até o décimo sétimo ano de seleção.

\section{CONCLUSÕES}

A seleção para crescimento e habilidade materna propiciou maiores incrementos nos dezessete primeiros anos nos índices de produção do sistema extensivo de criação de Nelore da Embrapa Cerrados, que nos últimos três anos simulados tenderam a estabilização. Mudanças no sistema nutricional ao final de dezessete anos de seleção são necessárias no sentido de aumentar o aporte de nutrientes permitindo assim que os animais continuem a demonstrar resposta efetiva aos critérios de seleção utilizados.

\section{REFERÊNCIAS}

ALENCAR, M.M. Critérios de seleção em bovinos de corte no Brasil. In: SIMPÓSIO NACIONALDE MELHORAMENTO ANIMAL, 4., 2002, Campo Grande. Anais... Campo Grande: SBMA, 2002.

ALENCAR, M.M.; BARBOSA, R.T.; NOVAES, A.P. de. Características produtivas e reprodutivas de fêmeas da raça Nelore e cruzadas $1 / 2$ Canchim $+1 / 2$ Nelore. Revista Brasileira de Zootecnia, v.28, n.5, p.960-967, 1999.

ALENCAR, M.M.; TREMATORE, R.L.; OLIVEIRA, J.A.L. et al. Desempenho Produtivo de Vacas da Raca Nelore e Cruzadas Charoles X Nelore, Limousin X Nelore e Tabapua X Gir. Revista Brasileira de Zootecnia, v.26, n.3, p.467-472, 1997.

FRIZZO, A.; ROCHA, M.G. da; RESTLE, J. et al. Suplementação energética na recria de bezerras de corte mantidas em pastagem de inverno. Revista Brasileira de Zootecnia, v.32, n.3, p. 643-652, 2003. 
HERD, D.B.; SPROTT, L.R. Body condition, nutrition and reproduction of beef cow. Texas Agricultural Extention Service Bulletin. Texas, p.3-11, 1996.

JORGE JÚNIOR, J.; CARDOSO, V.L.; ALBUQUERQUE, L.G. Modelo bioeconômico para cálculo de custos e receitas em sistemas de produção de gado de corte visando à obtenção de valores econômicos de características produtivas e reprodutivas. Revista Brasileira de Zootecnia, v.35, n.5, p.2187-2196, 2006.

LOBATO, J.F.P.; ZANOTTA JÚNIOR, R.L.D.; PEREIRA NETO, O.A. Efeito das dietas pré e pósparto de vacas primíparas sobre o desenvolvimento dos bezerros. Revista Brasileira de Zootecnia, v.27, n.5, p.863-867, 1998.

MAGNABOSCO, C.U.; LÔBO, R.B.; CALDAS, M.C.S.; Efeito do pai do bezerro nos desempenhos reprodutivo e produtivo da vaca. Brasília: Ed. EMBRAPA - SPI, 1994. 45p.

MAGNABOSCO, C.U.; BARIONI, L.G.; PAULINO, P.V.R. et al. Análise de decisão considerando diferentes méritos genéticos para touros em um rebanho da raça Nelore utilizando o programa DECI. In: REUNIÃO ANUAL DA SOCIEDADE BRASILEIRA DE ZOOTECNIA, 43., João Pessoa, 2006. Anais... João Pessoa: SBZ, 2006. CD ROM.

MARSHALL, T.E.; STEWART, T.S.; MARTIN, T.G. Optimal mature size of Angus cows for maximum cow productivity. In: INDIANA ASSOCIATION ANNUAL CONVENTION, 10., West Lafayette, 1983. Proceedings... West Lafayette: IAAC, p. 4348, 1983.

MARSHALL, T.E.; MOHLER, M.A.; STEWART, T.S. Relationship of lifetime productivity with mature weight and maturation rate in Red Poll cows.

Animal Production, v.39, n.3, p.383-387, 1987.

MARTINS, G.A.; MARTINS FILHO, R.; LIMA, F.A.M. et al. Influência de fatores genéticos e de meio sobre o crescimento de bovinos da raça Nelore no estado do Maranhão. Revista Brasileira de Zootecnia, v.29, p.103-107, 2000.

McMANUS, C.; SAUERESSIG, M.G.; FALCÃO, R.A. et al. Componentes reprodutivos e produtivos no rebanho de corte da Embrapa Cerrados.

Revista Brasileira de Zootecnia, v.31, n.3, p.648657, 2002.

MEIRELLES, F.D.P. Modelo computacional de um rebanho bovino de corte virtual utilizando Simulação de Monte Carlo e Redes Neurais Artificiais. 2005. 105f. Tese (Doutorado em Qualidade e Produtividade Animal) - Faculdade de Zootecnia e Tecnologia de Alimentos, Universidade de São Paulo, Pirassununga. 2005.
MERCADANTE, M.E.Z.; PACKER, I.U.; RAZOOK, A.G. et al. Dias ao parto de fêmeas Nelore de um experimento de seleção para crescimento. I Modelo de Repetibilidade. Revista Brasileira de Zootecnia, v.31, n.4, p.1715-1725, 2002.

MUNIZ, C.A.S.D; CARVALHEIRO, R.; FRIES, L.A. et al. Dois critérios de seleção na pré-desmama em bovinos da raça Gir: 1. Estimativas de parâmetros genéticos. Revista Brasileira de Zootecnia. v.34, n.3, p.807-815, 2005.

PERON, A.J.; EVANGELISTA, A.R. Degradação de pastagens em regiões de Cerrado. Ciência e Agrotecnologia. v.28, n.3, p.655-661, 2004.

RIBEIRO, E.L.A.; RESTLE, J. Desempenho de terneiros Charolês e Aberdeen Angus puros e seus mestiços com Nelore. Pesquisa Agropecuária Brasileira, v.26, n.8, p.1145-1151, 1991.

SCARPATI, M.T.V.; LÔBO, R.B. Modelos animais alternativos para estimação de componentes de (co)variância de parâmetros genéticos e fenotípicos do peso ao nascer na raça Nelore. Revista

Brasileira de Zootecnia. v.28, n.3, p.512-518, 1999.

SILVA, N.P.; OLIVEIRA FILHO, B.D.; GAMBARINI, M.L. Eficiência reprodutiva de primíparas suplementadas com fósforo, proteína e energia no pré e pós-parto. In: REUNIÃO ANUAL DA SOCIEDADE BRASILEIRA DE ZOOTECNIA, 42., 2005, Goiânia. Anais... Goiânia: SBZ, 2005. CDROM.

SILVEIRA, J.C.; MCMANUS, C.; MASCIOLI, A.S. et al. Fatores ambientais e parâmetros genéticos para características produtivas e reprodutivas em um rebanho Nelore no estados do Mato Grosso do Sul. Revista Brasileira de Zootecnia. v.33, n.6, p.14321444, 2004.

STATISTICAL ANALYSIS SYSTEMS - SAS. User's guide: Version 6, Cary: 1997. v.2, 1052p.

TALHARI, F.M.; ALENCAR, M.M.; MASCIOLI, A.S. et al. Correlações genéticas entre características produtivas em fêmeas em um rebanho da raça Canchim. Revista Brasileira de Zootecnia. v.32, n.4, p.880-886, 2003.

TESS, M.W.; KOLSTAD, B.W. Simulation of cowcalf production systems in a range environment: I Model development. Journal Animal Science, v.78, p.1159-1169, 2000.

VALLE, E.R., ANDREOTTI, R., THIAGO, L.R.L.S. Técnicas de manejo reprodutivo em bovinos de corte. Embrapa Gado de Corte. Documento 93. Campo Grande, 2000. 61p. 
VIU, M.A.O.; LOPES, D.T.; GAMBARINI, M.L. et al. Efeito da época do parto, idade materna e sexo sobre o desempenho pré-desmama de bezerros Nelore (Bos taurus indicus), criados extensivamente no Centro-Oeste do Brasil. Archives of Veterinary Science, v.11, n.3, p.75-79, 2006.

WILLIAMS, C.B.; JENKINS, T.G. Decision

Evaluator for the Cattle Industry. User's Guide and Software. 2000. Disponível em: <http://www.marc.usda.gov>. Acesso em 10/10/2008.

WILLIAMS, C.B.; BENNETT, G.L.; JENKINS, T.G. et al. Using simulation models to predict feed intake: Phenotypic and genetic relationships between observed and predict values in cattle. Journal of Animal Science, v.84, p.1310-1316, 2006. 